05

湤

\title{
REAL-WORLD LABORATORIES AS CATALYSTS FOR URBAN CHANGE
}

\section{The Example of CASA Schützenplatz in Stuttgart}

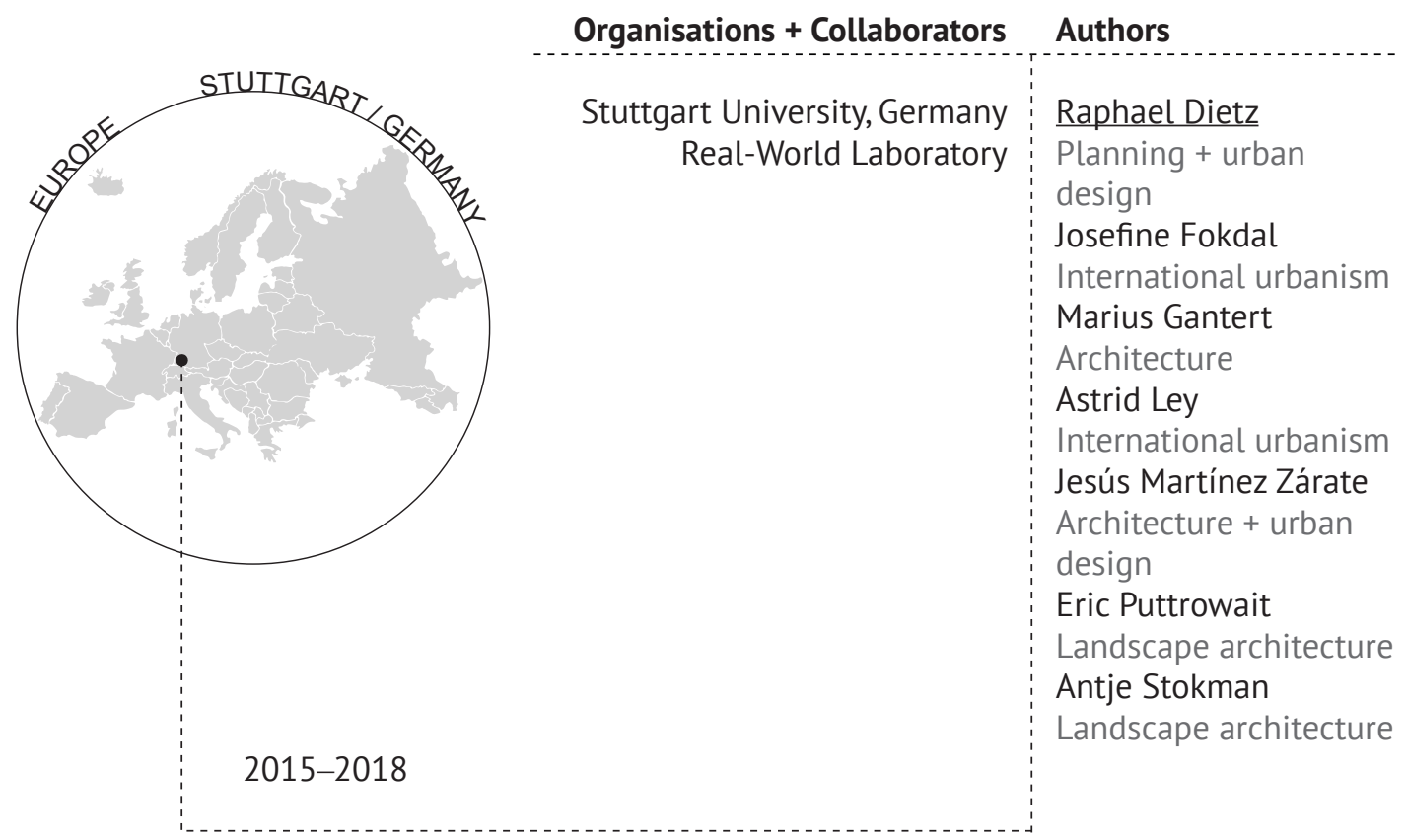

\section{Introduction}

The Sustainable Development Goals and the Paris Climate Agreement both call for an urgent improvement of environmental conditions and innovative solutions to move beyond business as usual with a strong emphasis on the role of cities and urban development. Tackling such great societal challenges requires innovative science and practice with a more integrative approach to knowledge generation. The past 20 years have shown that, both in development practice and academic research, closer cooperation between various actors is necessary to understand and impact the ongoing unsustainable urban development processes. It calls for new methods in urban research and practice, new forms of decision-making and a questioning of the normative understanding of knowledge production.

This is where co-production of knowledge as a means for coping with these challenges becomes relevant to ensure a more sustainable urban future. ${ }^{1}$ The term "co-production" covers a broader range of meanings.

FIGURE II.5.1 Brunch at Schützenplatz in July 2016. Photo by CASA Schützenplatz e.V. 
In this article, we rely on the following definition of co-production of knowledge within urban development processes: "Knowledge co-production refers to collaboratively-based processes where different actors and interest groups come together with researchers to share and create knowledge that can be used to address the sustainability challenges being faced today, and increase the research capacity to contribute to societal problem solving in the future" (Polk, 2016, p. 35). Thus, we see joint knowledge production as a promising mode of governance due to its questioning of normative perceptions of knowledge and knowledge generation, its innovative ${ }^{2}$ approach to relationship building and shared decision-making in practice and research, and the applicability of results to practice and policymaking.

Three discourses concerned with co-production of knowledge can be identified. The first perspective is the sustainability discourse, which opts for transformative science for sustainability and interdisciplinarity and new methods in research and practice to capture the increasing complexity of the urban reality of the 21st century (e.g. Cornell et al., 2013; Schneidewind \& Singer-Brodowski, 2014; Wiek, Talwar, O'Shea, \& Robinson, 2014; Wissenschaftlicher Beirat der Bundesregierung Globale Umweltveränderungen, 2016). It calls for inter- and transdisciplinary research to incorporate the complexity of unstructured problems and consequently the co-production of knowledge (e.g. Klein, 1994, 2004; Lawrence, 2010). The second strand is related to the urban development discourse within development studies, which recognises modes of co-production (service and knowledge) as a means of empowerment (e.g. Mitlin, 2008; Patel, 2004; Satterthwaite, 2005) and which is based in the roots of action research and participation. The third discourse in the field of planning theory sees modes of co-production as a new method beyond participation to overcome social inequalities (Robinson, 2002; Watson, 2003, 2012; Yiftachel, 2006; Herrle, Ley, \& Fokdal, 2015). Whereas previous theoretical approaches, such as communicative and collaborative planning, work inside the institutional framework, modes of co-production go beyond participation, and work outside the formal governance arena and help to expand the scope of planning thought (Watson, 2014).

The case of CASA Schützenplatz in Stuttgart, Germany, illustrated here, positions itself within the discourse on transformative science for sustainability, arguing that in order to tackle environmental issues related to mobility, one urgently needs to gain more insights into mobility cultures (Bott, Stokman, \& Uhl, 2015). The hypothesis is that using transformation experiments to establish a dialogue around sustainable mobility can potentially catalyse change in mobility cultures towards a more sustainable future.

\section{A Real-World Laboratory for a Sustainable Mobility Culture}

The University of Stuttgart hosts various real-world laboratories, one of them with a focus on sustainable mobility culture. This article will elaborate on one of the conducted transformation experiments related to sustainable mobility culture. Real-world laboratories are a new and innovative way of conducting transdisciplinary research financed by the state of Baden-Württemberg in Germany (Ministerium für Wissenschaft, Forschung und Kunst Baden-Württemberg, 2013). They are seen as one possible research strategy to enable inter-, transdisciplinary and transformative research (Wissenschaftlicher Beirat der Bundesregierung Globale Umweltveränderungen, 2011). As one of seven real-world laboratories in the first funding line (2015-17), the Real-World Laboratory for a Sustainable Mobility Culture (Reallabor Nachhaltige Mobilitätskultur - RNM) makes the city of Stuttgart a space for cooperative experimentation. Beyond researching and observing human patterns of mobility behaviour, it asks researchers to work together with local citizens, civil society 
and various departments of the municipality to develop and initiate real transformational processes in order to derive relevant practical knowledge and concrete solutions for the broader challenges concerning mobility facing society in the future.

Stuttgart is a city defined by cars. It is here that the largest automobile industry cluster in Europe provides employment for a great part of the regional workforce (Industrie und Handelskammer Region Stuttgart, 2017). Cars are therefore an important factor for the identity and economy of the city. At the same time, there is a growing awareness of the urgency of addressing the negative effects of vehicular transport - traffic jams, fine particle and CO2 emissions, land consumption, and noise pollution - and to move towards a more sustainable concept for mobility in the Stuttgart region. While previous municipal efforts focused on technological and efficiency aspects such as the promotion of car-sharing, electric vehicles and moderately successful campaigns for the voluntary renunciation of car use, the Real-World Laboratory for a Sustainable Mobility Culture made the cultural dimension of the transition towards a more sustainable urban mobility system its central theme. As such, its focus lay not on technologies or strategies for optimising traffic and transport systems, but on engendering a culture of mobility and activity that, in line with a broader understanding of prosperity, has the capacity to enhance our quality of life at a personal level and in the city as a whole. A sustainable culture of mobility aims not only to reduce the consumption of resources but also to promote health and physical activity, to encourage social interaction and to cultivate a new quality of life and urban space in the city and the region. Furthermore, it addresses the question of how the needs and rights of every individual to mobility could be implemented in such a way that later generations can also benefit from a healthy, liveable and intact environment. Following this definition and aiming to develop and evaluate innovative methodologies for transformative research, the overarching research questions of the Real-World Laboratory for a Sustainable Mobility Culture were: how could a transformational process be set in motion; which direction should it take; and what role could local citizens play in actively shaping and enabling this process through social innovations?

The Real-World Laboratory for a Sustainable Mobility Culture served as a forum and network for new partnerships. In addition to an interdisciplinary team of researchers and students from transportation planning and technology management, architecture and urban planning, sociology, and sports sciences, it also actively involved civil society initiatives, cultural institutions, stakeholders such as local businesses, associations and federations, as well as local city administration and policymakers in the research process. A special role was played by so-called "change agents" (Wissenschaftlicher Beirat der Bundesregierung Globale Umweltveränderungen, 2011) who were already actively developing and implementing social innovations and innovative sustainable mobility projects. Their actions have the capacity to change how we live on a day-to-day basis and serve as inspiration for others. In the case of CASA, a student and a couple of residents from Schützenplatz, who were already articulating their interest regarding a planned redesign of the square, acted as "change agents." The aim of the Real-World Laboratory for a Sustainable Mobility Culture as a platform for such niche innovators was to strengthen, promote and link up their projects and initiatives - and to jointly reflect on the experiences and results of the cooperative research process.

\section{The Experiment as a Method for Transdisciplinary Research}

Laboratories are made for experiments. In a real-world laboratory, the experiments take place in an actual (spatial) environment. Here, we will refer to these experiments as "transformation experiments" (Parodi et al., 2017, p. 80) in order to avoid the negative connotations that earlier use of 
the vocabulary "real-world experiment" has. Making the city a space for cooperative experimentation, they aim to explore what effects new ideas can bring about. Within urban planning there is a long tradition of participatory practice and research (e.g. collaborative planning or the communicative turn (Healey, 1993, 1997)). The real-world laboratories situate themselves within the tradition of action and intervention research (Parodi et al., 2017). Thus, as such, the Real-World Laboratory for a Sustainable Mobility Culture invited the people of Stuttgart to tackle the challenges of urban mobility and try out new possible solutions in the form of transformation experiments to examine how these influence a range of ecological, technical and social boundary conditions. This comparatively new research format focuses not only on researching and observing human patterns of behaviour, but also asks researchers to work together with local citizens to develop and initiate real transformation processes in order to derive relevant practical knowledge and concrete solutions for the broader challenges facing society in the future. Transformation experiments offer the opportunity to govern change and produce scientific evidence in parallel (Schäpke et al., 2017). In a multi-stage public participation process, local mobility initiatives and citizens worked together with students from the University of Stuttgart to develop a range of different transformation experiments. Following a call for ideas, a transdisciplinary jury was formed by members of the scientific staff, city administration, cultural and economic institutions, students' associations, and representatives of the target groups of the research project. Supplemented by a public vote the jury selected several projects for funding, ongoing monitoring and support (Puttrowait, Dietz, Gantert, \& Heynold, 2018). Members of the public were able to follow the progress of the experiments and contribute to or play an active part in the development. Transformation workshops were conducted to co-design research questions, define appropriate research methods, evaluate the success of the transformation experiments and reflect on their impact. Every transformation experiment concluded with a co-written report, which served as the basis of a comparative analysis and the formulation of the mechanisms of their impact on mobility transitions in Stuttgart.

Within the Real-World Laboratory for a Sustainable Mobility Culture, four transformation experiments were conducted and evaluated with "change agents" and their mobility initiatives:

- Cargo-Bikes as Urban Commons: The rotating cargo-bike

How could communally used bicycles contribute to forming cooperative neighbourhood structures and how could cargo-bikes help to reduce noise and particle emissions while making urban transport enjoyable? (Rudolf, Becker, \& Puttrowait, 2017).

- Cycling Without Age: The people's rickshaw

How could active mobility choices of elderly people be improved and how could transport bring people together instead of separating them? (Bleibler \& Brandt, 2016).

- The City as a House: The Stäffele gallery

How could Stuttgart's Stäffele ${ }^{3}$ be improved as places for movement and activity and how could they unfold further potential as meeting places for the neighbourhood or stages for cultural events? (Heynold, 2017).

- Reclaiming the Street: Parklets ${ }^{4}$ for Stuttgart

How could tightly parked inner-city streets be reclaimed as urban space and how could parklets encourage residents to recognise the street as a space for people to meet and interact? (Lazarova, Helfenstein, Dietz, \& Alcántara, 2018). 


\section{Learning Together and Co-Producing Knowledge}

Within this setting, the seminar "Stadtraum Stauraum Lebensraum" ${ }^{5}$ became a major component in the realisation of the transformation experiment "Reclaiming the street - Parklets for Stuttgart," implementing a practice-oriented learning approach. Practice-oriented learning is nothing new within the realm of planning education, with its twofold agenda of educating and generating societal change. Within higher education with a spatial focus, methods such as "service learning" (Altenschmidt \& Stark, 2016) and "case study" and "transition experiment" (van den Bosch \& Rotmans, 2008) approaches have increasingly gained momentum (Porter et al., 2015; Rooij \& Frank, 2016). Here, concepts such as "partnership for co-creation of knowledge" (Rooij \& Frank, 2016), "placebased co-creation of knowledge for sustainable development" (Trencher, Yarime, McCormick, Doll, \& Kraines, 2014) and "partnership for education" (Porter et al., 2015) are prominent. What they have in common are: 1) that they all include various disciplines, and non-academic partners as well as local communities. The main didactic aim is to facilitate an experimental learning environment and to foster inter- or transdisciplinary competencies (Porter et al., 2015; Rooij \& Frank, 2016); and 2) that they encourage students to develop problem-based solutions and to critically reflect on their role as planners.

Five major groups of actors were involved in the seminar and the experiment: the civil society actors $^{6}$ who were the driving force behind the parklet project (referred to from this point onwards as "Team Parklets for Stuttgart"); the academic staff of the Real-World Laboratory for a Sustainable Mobility Culture, mainly represented by the Institute of Urban Planning and Design; the Department of International Urbanism of the University of Stuttgart; students of architecture and urban planning; and local wardens who would later be responsible for the parklets and different departments of the city administration (for a more detailed display of the actors involved, see Lazarova et al., 2018). Team Parklets for Stuttgart and the academic staff of the Real-World Laboratory for a Sustainable Mobility Culture jointly took charge of organisational issues, supervision of the students' activities and consultations over their designs, selection of locations and contact with the local wardens, public communication (including local political committees) and the official overall permission for the project. They also supervised and conducted the data collection, analysed the different datasets and synthesised them into a research report (Lazarova et al., 2018).

Each student had to design a single parklet based on their analysis of the location and in coordination with the local wardens. With their design as a base, they had to apply for a separate permission for each single parklet and finally build the parklet. For this reason, they were granted a budget of $€ 400$ each, which was funded by the Real-World Laboratory for a Sustainable Mobility Culture. After the parklets were completed, they were officially inaugurated, including a public presentation from the student, and finally handed over to the local wardens. The student's responsibility now was to conduct research on their particular parklet. The methodology was set up together with scientists from urban and social sciences, sports sciences, transportation science, and geography at a transformation workshop at the beginning of the design studio and mainly focused on public life studies (Gehl \& Svarre, 2013).

The local wardens were responsible for observing their parklet, giving answers to any questions and maintaining the parklets during the experimental phase. They were also welcome to contribute to the construction by providing space, tools, manpower or financial help on a voluntary basis. After the parklets were demolished, the wardens took part in an interview with the research team to share their valuable experiences as those who had the best knowledge about "their" parklet. 
Finally, the city administration contributed by providing consultations, granting permission without charge and managing official complaints. The fact that this permission was justified by the scientific setting of the project makes clear that a private initiative would have barely been successful and that the scientific legitimation was key to enable the project.

As a result of this inter- and transdisciplinary design studio and transformation experiment, 11 parklets were realised and remained for a period of three months during the summer of 2016 in different locations in the inner-city districts of Stuttgart, causing a public discussion about how such functions in public space were distributed. One of these parklets was CASA Schützenplatz, which is described in detail below.

\section{CASA Schützenplatz}

Schützenplatz is a $1,300 \mathrm{~m}^{2}$ circular urban space in a semi-dense residential area of central Stuttgart. One of the major challenges is that the square is split by vehicles crossing (two intersecting roads) and strongly dominated by parked vehicles (49 parking spaces). However, there is weak mixed use in the surrounding ground floor buildings, with a good connection to public transportation at walkable distance and good population density, which are potential assets for becoming a vibrant active public space.

To challenge the status quo and to facilitate the reimagination of Schützenplatz as a high-quality public space, the transformation experiment "CASA Schützenplatz" was applied as an open-ended design, from April 2016 onwards, with the aim of generating knowledge about the specific context and catalysing synergies in a multi-stakeholder environment.

The initial experiment consisted of a physical project (the parklet) occupying two parking spaces and a series of analyses, campaigns and exercises that helped to gather data on the uses and types of mobility on Schützenplatz.

\section{The Experiment}

As this project on public space was meant to activate public life around it, four components were key for its strategic design:

- An understanding of the surroundings and its context: a previous scouting of the area and a basic knowledge of the potential of the public space.

- The community: the project should look to invite and involve the community in the process, capture their concerns for a human-scale public space design and their commitment to activate it.

- A basic pedestrian infrastructure: for the development of an active public space, the community should have access to basic features that allow time to be spent in the public space, like seating, shadowing, communal information. In this case, those features were provided by the parklet. In the second phase (autumn/winter), seasonal differences became an issue and led to adding a roof and changing the furniture in the parklet.

- A programme: a series of constant activities and meet-ups that tested in how many different ways the public space could be used, looking to reinforce the potential that a public space has to generate and keep active communication among a community. 


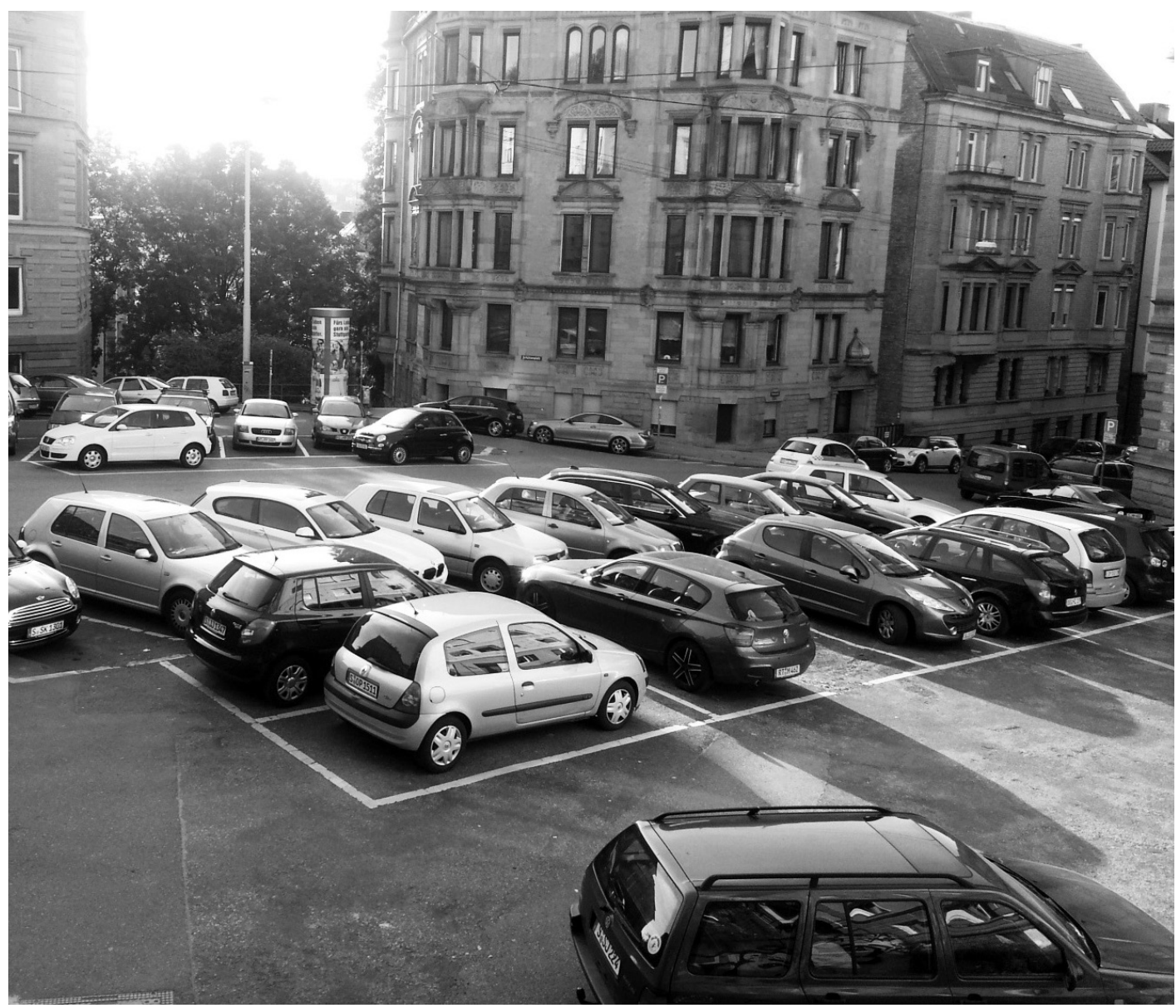

FIGURE II.5.2 First walks in the neighbourhood before the intervention. May 2016. Photo by CASA Schützenplatz e.V.

The transformation experiment approach not only monitored the feedback generated in a scientific manner, but also actively contributed to its improvement. Qualitative data were generated through an active interaction with the community and quantitative data through monitoring of the surroundings by the student. This mixed-methods approach, in combination with a temporary physical project in the shape of a parklet, served as a catalyst for the experiment. ${ }^{7}$ The different phases of the experiment are described below.

Phase 01: 01 April-16 September 2016 - The parklet CASA Schützenplatz

The original experiment: in this case, Phase 01 was meant to last three months, during which the parklet was situated in the public space. In preparation, field research and analyses took place in the first two months to better understand the dynamics in the square. This included mapping and analysis of 1) the number of pedestrians crossing and using the square as well as the number of vehicles crossing; 2) a mapping of how pedestrians moved across Schützenplatz at different 


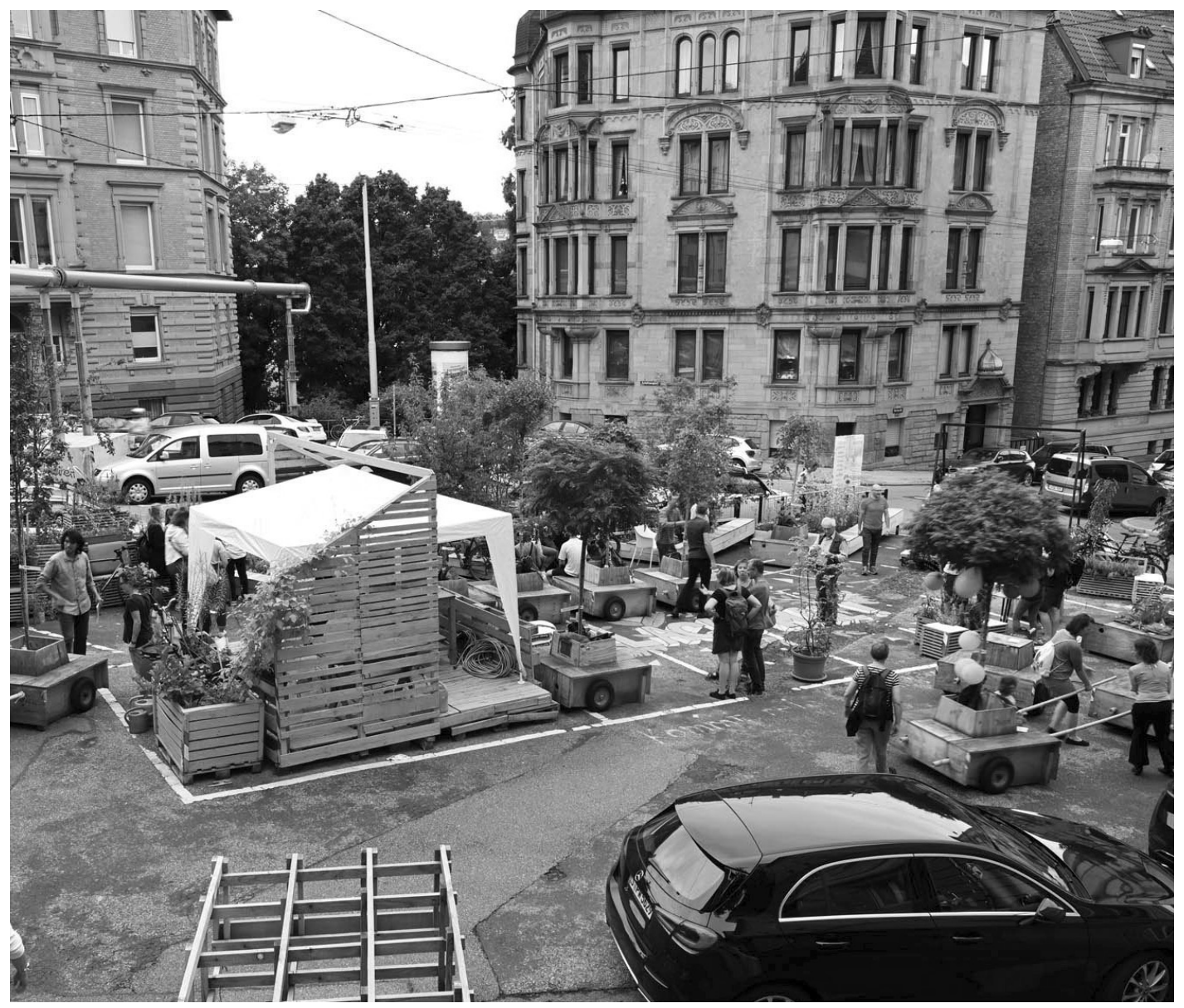

FIGURE II.5.3 Schützenplatz e.V. and initiative Wanderbaumallee Stuttgart create the temporary intervention, City forest in Schützenplatz. August 2018. Photo by CASA Schützenplatz e.V.

times of the day; and 3) an observation of how many parking movements occurred throughout the day and how long the cars stayed parked. In the next months, from July to mid-September, the parklet was installed and the first intended on-field analyses took place.

Phase 02: 17 September-30 October 2016 - Extension of the experiment

An extraordinary petition was granted by the city authorities to extend the permission for the parklet. At that time, the community decided to continue the experiment, still assisted by the Real-World Laboratory for a Sustainable Mobility Culture but now under community responsibility.

Phase 03: November 2016-March 2017 - Neighbourhood initiative CASA Schützenplatz

The residents organised in a formal manner to seek support among the neighbourhood, other organisations and the authorities. At this particular stage, it was possible to rent a store facing the square. This allowed the initiative to have a headquarters and allowed them to continue an activities programme. 


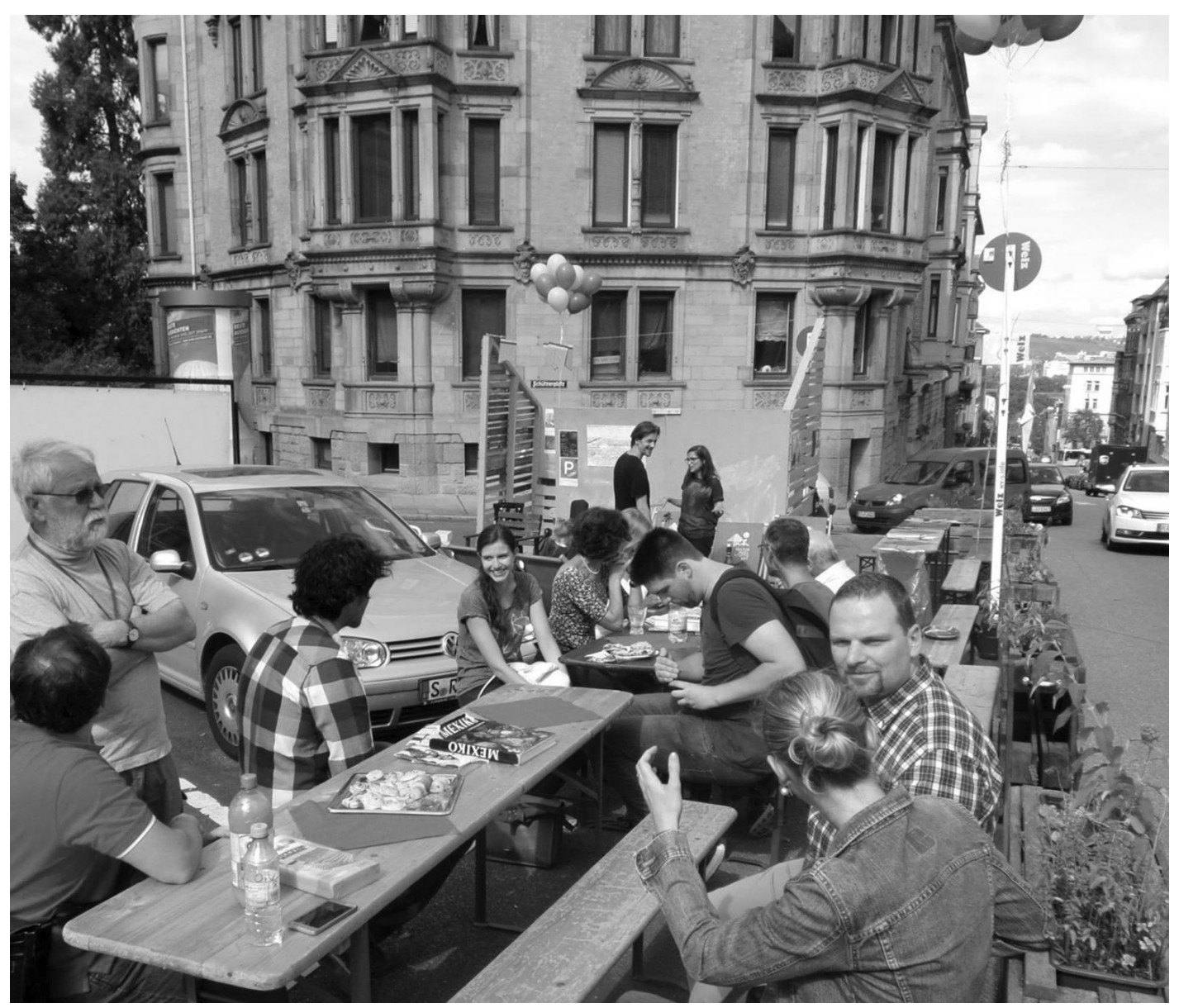

FIGURE II.5.4 Street festival at the Schützenplatz with dancing and movie screening on "parking day." Photo by CASA Schützenplatz e.V.

Phase 04: April 2017-February 2018 - CASA Schützenplatz e.V.

The legal status of the initiative was fully formalised with the foundation of the registered organisation CASA Schützenplatz e.V. ${ }^{8}$ The two main objectives of the association are 1) to pursue the conclusion of the square's refurbishment and 2) to maintain a community network.

To trigger reactions and test the value of public space in the community, small campaigns took place during Phases 01 and 02 aimed at generating knowledge about the physical context and the neighbourhood, and at actively showing the potential of the space by using it as an arena for activities, gatherings and discussions.

These campaigns were based on two complementary approaches to public space design: placemaking to understand the space qualitatively (e.g. Whyte, 1980), and public space-public life studies to explain it quantitatively (e.g. Gehl \& Svarre, 2013). 
Campaign A: From brunches to workshops

This consisted of a series of organised events in the parklet that transited from informal gatherings to organised workshops in a span of three months with a threefold purpose:

inhibiting the activation of the new public space, initiating the dialogue with and between the community about the value of an active public space in Schützenplatz, and spotting key actors in the local community.

Campaign B: Interactive boards

Inside the facades of the parklet, two blackboards were intended to generate some passive interactions by asking two different questions, one regarding the potential that the neighbourhood saw for the square: "What do we need at Schützenplatz?" and one regarding the potential the neighbours saw for other uses in the public space: "How do you use CASA?"

Campaign C: Neighbourhood festival in the public space

With the intention of scaling up the potential of the public space to host different activities, a neighbourhood festival with diverse and more spatial activities took place for one day.

With these interactive campaigns, the neighbourhood grasped the potential of their public space and the value of regular gatherings for the engagement and enhancement of an active community in a long city development process. Such interaction gave a quick overview of how the community felt about the public space in their proximity. At the same time, the mapping and observations helped to show the ineffectiveness of space occupied by vehicles and the hostile environment left for pedestrians. The information helped to establish a fair base for negotiation with the city authorities about the need for a change in priorities set in the public space at Schützenplatz. The actual situation is about to change in Schützenplatz! The refurbishment of the area, delayed already for 15 years, is planned to happen in summer 2019. ${ }^{9}$ For this refurbishment, the community was able to achieve a prominent role in the last step of the design as decision-makers (furniture and minor details). Their role as a knowledge source for the design of the area was increased by the data generated during the experiment.

\section{Enabling Conditions for Co-Producing Knowledge at CASA Schützenplatz}

Several lessons can be learned from this case. First, a set of enabling conditions can be identified related to the experiment Parklets for Stuttgart in general, and second, the specific condition of an already concerned and organised group of residents:

- The scientific setting of the interdisciplinary real-world laboratory served for legitimisation both of the permission from the authorities to occupy parking spaces in the city of Stuttgart and of the acceptance of the civil actors by the administration and politicians (which included a leap of faith). By the example of CASA Schützenplatz, the experiment was able to strengthen community ties, generating acceptance of the installed parklet, and encouraged discussion about the transformation of the public space with an active community around it during the first phase. Since the initial phase created enough momentum, the experiment extended into further phases with a more independent community and a more detached but still present interdisciplinary research body that was in constant contact with the authorities to negotiate and build trust. Even though the future sustainability of the project cannot be assured after the transformation experiment, it is clear that the new levels of participation and appropriation achieved so far will increase Schützenplatz's chances to become an active public space. 
- Building trust, providing legitimacy: That the transformation experiments could be carried out required a leap of faith on the part of the administration who granted permission. This leap was based on the reputation of the university that functioned as a door opener. Two factors can be named here:

1. The official permission for the parklets was justified by the "freedom of science," which is one of the highest values in German democracy, a higher value than the personal rights of the citizens to park their cars in public space.

2. The city was a partner in the research projects and city representatives were actively involved in taking the decision over which experiments were to be conducted, including the parklets. In retrospect, some city representatives told us informally that such projects would never have been allowed if a (group of) private person(s) had applied for it, but that the involvement of the university was key.

By presenting the findings ${ }^{10}$ to the administration and political stakeholders, this leap of faith was retrospectively justified, which was key for the continuation of the project as well as for upcoming new projects to prevent a "scorched earth" phenomenon. In addition, trust and legitimacy among the community were confirmed to be a key aspect of the continuation of the experiment.

- The importance of data: It is important to remark on the value of the generated data to the sustainability of the project. Appropriation and facts are now arguments that the community can use to empower themselves and become a trustworthy stakeholder in the decision-making process. This is a common aspect discussed in development studies focusing on the power of knowledge and information held by civil society actors in order to negotiate with local authorities (Herrle et al., 2015; Ley, Fokdal, \& Herrle, 2017). The combination of the data collected and the sense of appropriation generated by the neighbourhood at Schützenplatz strengthened the arguments from both the research body (the Real-World Laboratory for a Sustainable Mobility Culture) and the community about the need of such an approach for public space design and legitimised the experiment in the eyes of the city authorities and social organisations.

- Initial funding: The transition experiment Parklets for Stuttgart was supported with initial and clearly limited funding from the university of $€ 5000$. This was helpful for the acquisition of material for the construction of the parklets that could not have been raised gratis. It lowered the financial involvement of the actors and so required mainly personal participation. It also signalled the involvement and the will of the university to truly realise the project and in that way made it easier to convince further potential participants. In the case of CASA Schützenplatz, it finally led to the development that the neighbours looked out for alternative ways of funding for the continuation of the project.

- Fertile ground: The original experiment at CASA Schützenplatz has been turned into a formalised neighbourhood association that seeks to strengthen a community network and the active use of public space. The interactive campaigns applied during Phases 01 and 02 have become part of the core activities of the initiative: brunches, weekly gatherings, neighbourhood festivals, etc. The benefits of an active community for the quality and maintenance of the public space are clear. The community have created a cooperative environment around the process, inviting others, proposing new experiments and networking with other programmes and organisations. One major "fertile seed" was the student who engaged and acted as a "change agent" to mobilise and build trust within the community.

- Participation of students: Finally, the integration of the transformation experiment into academic teaching helped to find motivated students who put their creativity and technical knowledge into the design and, of course, provided the manpower that was necessary for the construction itself. In return, they gained precious experience by leaving the theoretical framework and presenting their ideas to the public, and realised the possibility of combining their educational efforts with a socially relevant topic. 
One of the major challenges both for the parklet project as a whole and for CASA Schützenplatz in the beginning was the resistance within the public to occupying parking spaces in inner-city locations in Stuttgart: people who agreed with the proposed changes tended to remain quiet, while opponents raised their voices. Thus, a few loud protests may produce the false image of a broad opposition against a small fraction of supporters. Therefore, projects with such a potential for political conflict need careful preparation in terms of collecting and communicating arguments for their relevance. One key finding on the topic of "opposition" is that the long process helped to ease the "noise" created by the first wave of negative feedback and also gave the project time to create its legitimisation. Now that there is a group of neighbours meeting regularly, either in the parklet or in the e.V. headquarters, and an organisation was created to maintain and administer the "new public space," the complaints have almost disappeared. The outcome would have been totally different if the experiment had finished after the three months, as the pieces of negative feedback concerning the parklet were still fresh and numerous. Furthermore, the experiment had not yet reached a sufficient level of engagement to sustain itself.

\section{Conclusions}

Besides the scientific aims of gaining systematic knowledge about the transformative potentials of "parklets" to repurpose parking space as public space for people, the aim of the transformation experiment in terms of its societal impact was twofold:

1. In the specific context of Schützenplatz, the aim was to change the dynamics among the relevant local stakeholders (residents, city planners and users) and to open up a space of negotiation through a spatial project - CASA Schützenplatz. CASA was a "parklet" occupying two parking spaces for a period of three months; however, this temporary experiment functioned as a catalyst for change with a long-term impact. Here, the role of science as a mediator between actors on different levels (engaged citizens and local authorities) became explicit and allowed for a more constructive dialogue between supporters and opposition. The CASA Schützenplatz transformation experiment helped to activate public life around Schützenplatz by empowering the neighbours with a sense of appropriation and by co-producing knowledge about their public space. Thus, it essentially contributed to the legitimisation of the community before city authorities.

2. Within the framework of a larger project on parklets in Stuttgart, the aim was to create awareness and a public debate around the quality of public space that could be increased by limiting motorised private transport and the urban space claimed exclusively for parking. One major achievement of the parklet project was to win over the local authorities to a culture of experimentation in spite of critical voices and protests from local residents and media.

Thus, joint knowledge production in this case pushed for improved relationship building with local authorities and for shared decision-making processes concerning the future of Schützenplatz in Stuttgart. Using the transformative approach of experiments as part of a transdisciplinary process established a dialogue around the quality and sustainability of a public space dominated by car mobility and catalysed a rethinking towards a more sustainable future at a very local scale.

\section{Notes}

1 Urban sustainability encompasses the basic values of environmental quality, economic dynamism and social justice, and requires their application to areas including transportation, land use, urban form, architecture and building construction practices (Wheeler \& Beatley, 2009), and it is often equated with more 
compact, socially inclusive, better integrated and connected cities and territories that are resilient to climate change (United Nations Human Settlement Programme, 2014). In this context, by sustainable urban development we refer to environmental justice, economic improvement and social equity as reflected in evolving urban systems (i.e. buildings, towns, cities and their infrastructures).

2 Rammert et al. (2016) differentiate between "Innovation überall" (innovation all over), "Innovation aller Art" (innovation of all kinds) and "Innovation jederzeit" (innovation at any time). They define "innovation" as a dynamic social process with sociological relevance; thus, beyond the traditionalist technological understanding of innovation and towards "innovation zones" that bridge various dimensions (e.g. social, technological, institutional and economic). Here, innovation is understood as new modes of knowledge production that are embedded in the triangle between politics, planning and civil society and that seek to break with existing routines and practices. These modes include practices that are not generally recognised and established as common within the field of urban development; thus, a generic understanding of planning as defined by Christmann, Ibert, Jessen, and Walther (2016).

3 Local name for public staircases that were formerly used to connect the many vineyards in the hilly setting of Stuttgart and nowadays play an important role for pedestrian connectivity within the city of Stuttgart. However, many of them suffer from a lack of maintenance and are therefore in a rather poor condition.

4 "Parklets repurpose part of the street next to the sidewalk into a public space for people. These small parks provide amenities like seating, planting, bicycle parking, and art" (City of San Francisco - Pavement to Parks Program, 2015, p. 3).

5 City space - congested space - living space.

6 Three architectural students at the University of Stuttgart, who put their private effort into the project.

7 On the metalevel, a comparative analysis of all the parklets was conducted, as was the public discussion. It included a content analysis conducted by a sociologist. In addition, interviews with the different "Wardens" about their observations were conducted.

8 e.V. is an abbreviation for "eingetragener Verein" and means a registered non-profit association.

9 At the date of publication, the refurbishment has again been postponed to 2024. Meanwhile CASA Schützenplatz still occupies the square and has grown from the single parklet to a semi-formal public space including an urban gardening initiative and hosting diverse community events on a regular basis (https:// schuetzenplatz.net/).

10 Regarding the main results, there are roughly three layers, regarding: A) the Real-World Laboratory for a Sustainable Mobility Culture as a whole, B) the Parklets project, C) Casa Schützenplatz.

A) See Reallabor Nachhaltige Mobilität (2018).

B) Public life studies for all the parklets, feedback and interviews with the local partners. Analysis of public discussion.

C) Public life studies from the student, who was in charge of the CASA parklet, including pedestrian counts, movement tracking, observation of activities, etc. A and B were presented at various occasions to city representatives, and ultimately at the Umwelt und Technikausschuss (UTA) when the Real-World Laboratory for a Sustainable Mobility Culture was completed. C was presented to the local district council (Bezirksbeirat Mitte) as part of the argumentation for extending the permission (which was granted).

\section{References}

Altenschmidt, K. \& Stark, K. (Eds.). (2016). Forschen und Lehren mit der Gesellschaft: Community Based Research und Service Learning an Hochschulen. Wiesbaden: Springer.

Bleibler, E., \& Brandt, O. (2016). Realexperiment Bürger-Rikscha. Stuttgart: Reallabor für nachhaltige Mobilitätskultur. Retrieved 19 July 2018 from http://www.r-n-m.net/wp-content/uploads/2018/03/DieBuerger-Rikscha.pdf.

Bott, H., Stokman, A., \& Uhl, E. (Eds.). (2015). Nachhaltige mobilitätskultur - Stadtraum, Mobilität und Gesundheit. Stuttgart: IZKT.

Christmann, G., Ibert, O., Jessen, J., \& Walther, U.-J. (2016). Wie kommt Neuartiges in die räumliche Planung? Konzeptionierung von Innovationen in der Planung und Forschungsstrategien. In: Rammert, W., 
Windeler, A., Knoblauch, H., \& Hutter, M. (Eds.). Innovationsgesellschaft heute. Wiesbaden: Springer, 273-300.

City of San Francisco - Pavement to Parks Program. (2015). San Francisco - Parklet manual (2nd ed.). San Francisco: City of San Francisco - Pavement to Parks Program. Retrieved 19 July 2018 from http://pavementtoparks.org/wp-content/uploads//2015/12/SF_P2P_Parklet_Manual_2.2_FULL1. pdf.

Cornell, S., Berkhout, F., Tuinstra, W., Tàbara, D., Jäger, J., Chabay, I., Wit, B.D., Langlais, R., Mills, D., Moll, P., Otto, I. M., Petersen, A., Pohl, C. \& Kerkhoff, L.V. (2013). Opening up knowledge systems for better responses to global environmental changes. Environmental Science and Policy, 28, 60-70.

Gehl, J., \& Svarre, B. (2013). How to study public life. Washington, DC: Island Press.

Healey, P. (1993). Planning through debate: The communicative turn in planning theory. In: Fischer, F., \& Forester, J. (Eds.). The argumentative turn in policy and planning. Durham, NC: Duke University Press.

Healey, P. (1997). Collaborative planning: Shaping places in fragmented societies. London: Macmillan.

Herrle, P., Ley, A., \& Fokdal, J. (Eds.). (2015). From local action to global networks: Housing the urban poor. London: Ashgate.

Heynold, J. (2017). Realexperiment Stäffele-Gallery. Stuttgart: Reallabor für nachhaltige Mobilitätskultur. Retrieved 19 July 2018 from http://www.r-n-m.net/wp-content/uploads/2018/03/Die-Staeffele-Gallery_web.pdf.

Hirsch Hadorn, G., Hoffmann-Riem, H., Biber-Klemm, S., Grossenbacher-Mansuy, W., Joye, D., Pohl, C., Wiesmann, U. \& Zemp, E. (Eds.) (2008). Handbook of transdisciplinary research. Berlin: Springer.

Industrie und Handelskammer Region Stuttgart (2017). Wirtschaftsregion Stuttgart - Zahlen und Fakten: Unternehmen, Betriebe und Beschäftigte (Unternehmensregister). Stuttgart: Industrie und Handelskammer Region Stuttgart. Retreived 09 August 2018 from https://www.stuttgart.ihk24.de/blob/sihk24/ standort_region_stuttgart/fakten/Statistik_nach_Themen/Unternehmensstatistik/690064/6c66428bdac 1b747b4a77450f08a9473/Unternehmen_Betriebe_und_Beschaeftigte-data.pdf.

Klein, J.T. (1994). Notes toward a social epistemology of transdisciplinarity. The International Center for Transdisciplinary Research (CIRET). Retrieved 22 May 2013 from http://ciret-transdisciplinarity.org/ bulletin/b12c2.php.

Klein, J.T. (2004). Prospects for transdisciplinarity. Futures, 36, 515-526.

Lawrence, R.J. (2010). Deciphering interdisciplinary and transdisciplinary contributions. Transdisciplinary Journal of Engineering and Science, 1, 125-130.

Lazarova, K., Helfenstein, B.S., Dietz, R., \& Alcántara, S. (2018). Parklets für Stuttgart - ein Realexperiment. Stuttgart: Reallabor für nachhaltige Mobilitätskultur. Retrieved 19 July 2018 from http://www.r-n-m. net/wp-content/uploads/2018/03/Parklets-fuer-Stuttgart_web.pdf.

Ley, A., Fokdal, J., \& Herrle, P. (2017). Whose best practise? Learning from transnational networks of urban poor. Trialog, 122(3), 24-27.

Ministerium für Wissenschaft, Forschung und Kunst Baden-Württemberg (MWK). (2013). Wissenschaft für Nachhaltigkeit. Retrieved 29 August 2018 from https://mwk.baden-wuerttemberg.de/fileadmin/ redaktion/m-mwk/intern/dateien/pdf/Wissenschaft_für_Nachhaltigkeit/Expertenbericht_RZ_ MWK_Broschuere_Nachhaltigkeit_Web.pdf.

Mitlin, D. (2008). With and beyond the state - co-production as a route to political influence, power and transformation for grasroots organizations. Environment \& Urbanization, 20, 339-360.

Parodi, O., Beecroft, R., Albiez, M., Quint, A., Seebach, A., Tamm, K., \& Waitz, C. (2017). The ABC of realworld lab methodology: From "action research" to "participation" and beyond. Trialog, 3-4(126/127), 74-82.

Patel, S. (2004). Tools and methods for empowerment developed by slum and pavement dwellers' federations in India. Participative Learning and Action, 50, 117-130.

Polk, M. (2016). How to manage complexity: Co-producing knowledge for urban change. In: Palmer, H., Walasek, H. (Eds.). Co-production in action: Towards realising just cities. Gothenburg: Mistra Urban Futures.

Porter, L., Slade, C., Butt, A., Rosier, J., Perkins, T., Crookes, L., Inch, A., Slade, J., Bassa, F., Petzer, B., Winkler, T., Saija, L., \& Barry, J. (2015). Partnerships of learning for planning education. Who is learning what from whom? The beautiful messiness of learning partnerships/Experiential learning partnerships in Australian and New Zealand higher education planning programmes/Res non verba? rediscovering the social purpose of planning (and the university): The Westfield Action Research Project/At the coalface, Take 2: Lessons from students' critical reflections/Education for "cubed change"/Unsettling planning education through community-engaged teaching and learning: Reflections on the indigenous planning studio. Planning Theory \& Practice, 16(3), pp. 409-434.

Puttrowait, E., Dietz, R., Gantert, M., \& Heynold, J. (2018). Der Weg zum Realexperiment - Schlüsselakteure identifizieren, Kooperationsstrukturen aufbauen, Projektideen auswählen. In: Defila, R., \& Giulio, A.D. (Eds.). Transdisziplinär und transformativ forschen: Eine Methodensammlung (pp. 195-232). Wiesbaden: Springer VS. https://doi.org/10.1007/978-3-658-21530-9_11. 
Rammert, W., Windeler, A., Knoblauch, H., \& Hutter, M. (Eds.). (2016). Innovationsgescllschaft heute. Perspektiven, Felder und Fälle. Wiesbaden: Springer.

Reallabor für nachhaltige Mobilitätskultur. Uni Stuttgart. (2018). Stuttgart in Bewegung: Berichte von unterwegs. Berlin: Jovis.

Robinson, J. (2002). Global and world cities: A view from off the map. International Journal of Urban and Regional Research, 26, 531-554.

Rooij, R., \& Frank, A.I. (2016). Educating spatial planners for the age of co-creation: The need to risk community, science and practice involvement in planning programmes and curricula. Planning Practice \& Research, 31(5), 473-485.

Rudolf, C., Becker, T., \& Puttrowait, E. (2017). Realexperiment Rotierendes Lastenrad. Stuttgart: Reallabor für nachhaltige Mobilitätskultur. Retrieved 19 July 2018 from http://www.r-n-m.net/wp-content/uploads/2018/03/Das-rotierende-Lastenrad.pdf.

Satterthwaite, D. (2005). Meeting the MDGs in urban areas: The forgotten role of local organizations. Journal of International Affairs, 58, 87-112.

Schneidewind, U., \& Singer-Brodowski, M. (2014). Vom experimentellen Lernen um transformativen Experimentieren. Zeitschrift für Wirtschafts- und Unternehmensethik 16 (1), 10-23.

Schon, D.A. (1987). Educating the reflective practitioner: Toward a new design for teaching and learning in the professions. San Francisco: Jossey-Bass.

Schäpke, N., Stelzer, F., Bergmann, M., Singer-Brodowski, M., Wanner, M., Caniglia, G., \& Land, D. (2017). Reallabore im Context transformativer Forschung: Ansatzpunkte zur Konzeption und Einbettung in den internationalen Forschungsstand. (No. 1/2017). Lüneburg, Germany: Leuphana Universität Lüneburg, Institut für Ethik und Transdisziplinäre Nachhaltigkeitsforschung.

Sletto, B. (2010). Educating reflective practitioners: Learning to embrace the unexpected through service learning. Journal of Planning Education and Research, 29(4), 403-415.

Trencher, G., Yarime, M., McCormick, M.B., Doll, C.N.H., \& Kraines, S.B. (2014). Beyond the third mission: Exploring the emerging university function of co-creation for sustainability. Science and Public Policy, 41(2), 151-179.

United Nations Human Settlement Programme (UN-HABITAT). (2014). The city we need. Nairobi: United Nations Human Settlement Programme.

Van den Bosch, S., \& Rotmans, J. (2008). Deepening, broadening and scaling up: A framework for steering transition experiments. (Essay 02). Knowledge Centre for Sustainable System Innovations and Transitions. Retrieved 25 May 2017 from http://hdl.handle.net/1765/15812.

Watson, V. (2003). Conflicting rationalities: Implications for planning theory and ethics. Planning Theory \& Practice, 4, 395-407.

Watson, V. (2012). Planning and the "stubborn realities" of global south-east cities: Some emerging ideas. Planning Theory \& Practice, 12, 81-100.

Watson, V. (2014). Co-production and collaboration in planning - The difference. Planning Theory, 15, $62-76$.

Wheeler, S.M., \& Beatley, T. (Eds.) (2009). The sustainable urban development reader. London: Routledge.

Whyte, W.H. (1980). The social life of small urban spaces. New York: Project for Public Spaces.

Wiek, A., Talwar, S., O'Shea, M., \& Robinson, J. (2014). Towards a methodological scheme for capturing societal effects of participatory sustainability research. Research Evaluation, 23, 117-132.

Wissenschaftlicher Beirat der Bundesregierung Globale Umweltveränderungen (WBGU) (2011). World in transition - a social contract for sustainability. Flagship Report 2011, German Advisory Council on Global Change (WBGU), Secretariat. Retrieved 01 January 2012 from http://www.wbgu.de/en/flagship-reports/fr-2011-a-social-contract/.

Wissenschaftlicher Beirat der Bundesregierung Globale Umweltveränderungen (WBGU) (2016). Humanity on the move: Unlocking the transformative power of cities. Flagship Report 2016, Advisory Council on Global Change (WBGU), Secretariat. Retrieved 01 August 2017 from http://www.wbgu.de/en/fr2016.

Yiftachel, O. (2006). Re-engaging planning theory towards "south-eastern" perspectives. Planning Theory, $5,211-222$. 